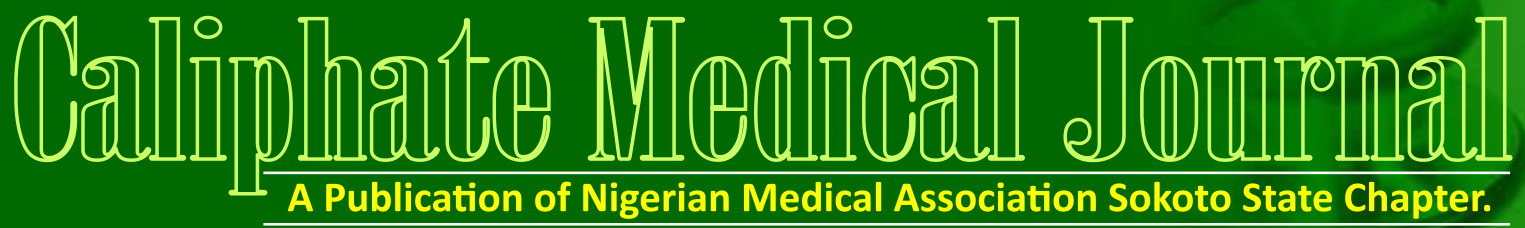

Vol 9, No. 2, April - June, 2021

ISSN: 2346

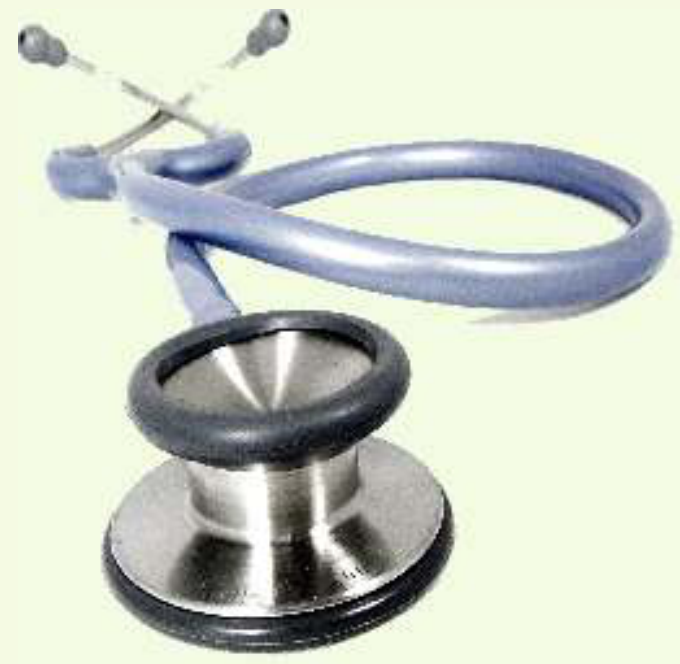

In this Issue
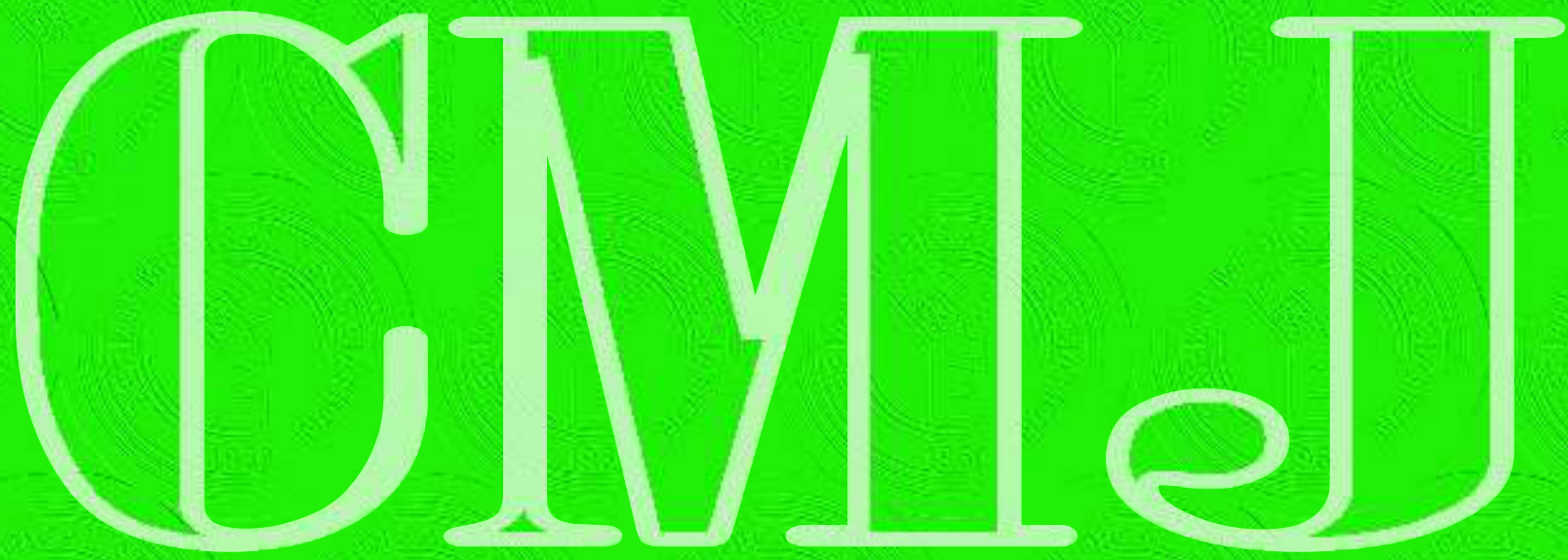


\title{
COMMUNITY BASED SURVEY OF BREASTFEEDING PRACTICES IN SOKOTO, NORTH-WESTERN NIGERIA
}

\author{
Jiya FB ${ }^{1}$, Ango $\mathrm{UM}^{2}$, Adamu $\mathrm{IB}^{2}$, Tukur $\mathrm{UM}^{3}$, Auwal $\mathrm{UA}^{2}$, Muhammad BM², Adamu A ${ }^{1}$, Isezuo KO
}

${ }^{1}$ Department of Paeditrics, Usmanu Danfodiyo University, Sokoto, Sokoto State ${ }^{2}$ Department of Community Health, Usmanu Danfodiyo University Teaching Hospital, Sokoto ${ }^{3}$ Department of Pharmacology, Usmanu Danfodiyo University, Sokoto, Sokoto State.

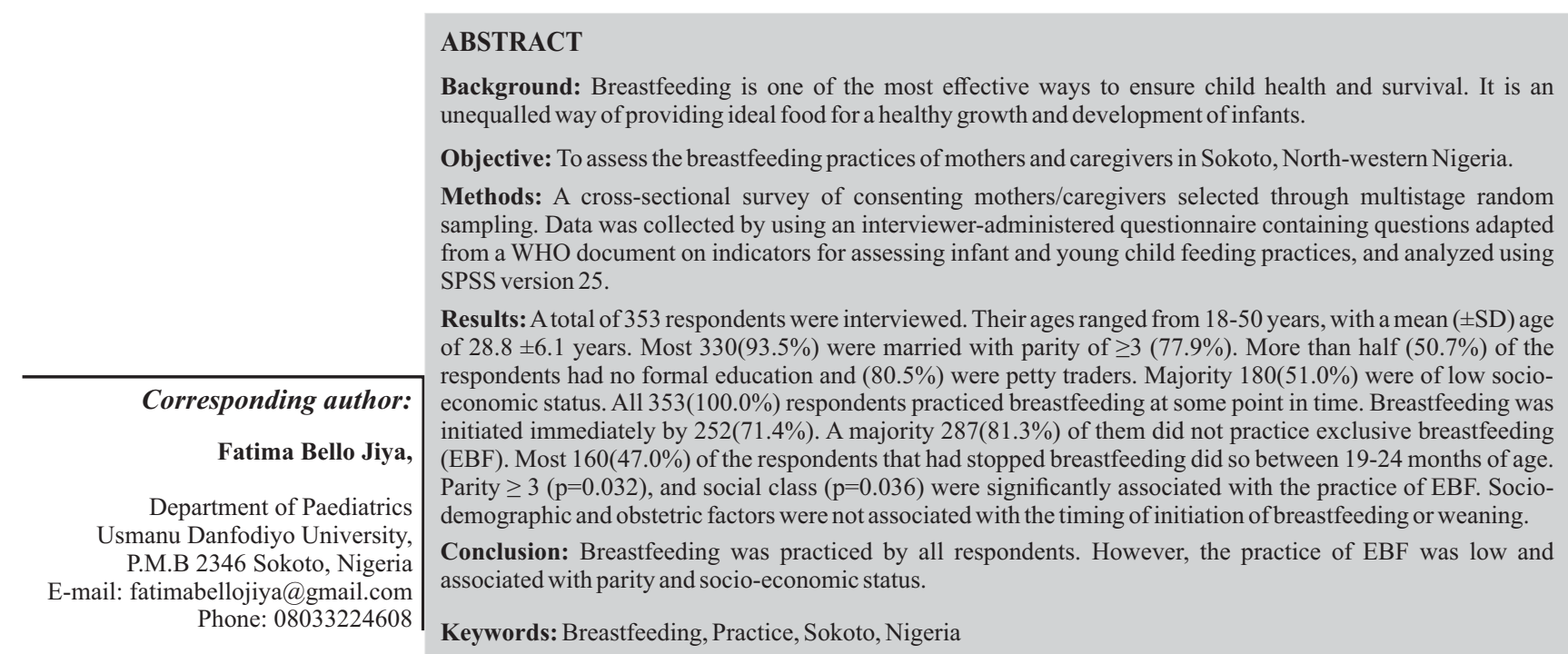

\section{Introduction}

E arly initiation of breastfeeding within the first hour of life, exclusive breastfeeding for the first 6 months of life, continued breastfeeding for 2 years or more, and introduction of safe, appropriate, and adequate complementary foods at age 6 months are all examples of appropriate infant and young child feeding (IYCF) practices. ${ }^{1}$ Breast milk provides all of the energy and nutrients that an infant requires during the first few months of life, and it continues to provide up to half or more of a child's nutritional needs during the second half of the first year, and up to one-third of a child's nutritional needs during the second year. ${ }^{2}$ Longer-term benefits include reduced risk for obesity, diabetes, asthma and dermatological diseases in children. ${ }^{3}$ Breastfeeding is directly linked to two of the SDGs, which focus on improved nutrition, and maternal and child health, respectively.

Despite the numerous advantages of breast milk and World Health Organization (WHO) recommendation that babies be exclusively breastfed for their first 6 months of life, nearly two out of three infants are said not to be exclusively breastfed for the recommended six months. Breastfeeding practices vary worldwide. In Indonesia, $95.7 \%$ of the children were breastfed with $50 \%$ of the infants being exclusively breastfed. The mean duration of breastfeeding was 18-24 months among the studied subjects. ${ }^{4}$ In Mexico, Latin America, $48 \%$ of infants $0-5$ months of age are fed with infant formula and only $35 \%$ of children under two years of age are breastfed. ${ }^{5}$ In Nigeria, the rate of breastfeeding ranged from $93.8 \%$ to $100 \%{ }^{6-9}$ However, the rate of exclusive breastfeeding is low and declining, ${ }^{6-11}$ with previous studies either focusing on exclusive breastfeeding in a single rural community set-up, or hopsital based, making the findings unlikely to be a true reflection of the practices in the community. ${ }^{8,12,13}$ Hence, this study assessed breastfeeding practices of mothers and caregivers within Sokoto in a household survey.

\section{Materials and Methods}

The study was a cross-sectional survey involving mothers/caregivers who resided in the study area for at least 1 year. This study was conducted in Sokoto state, Northwestern Nigeria from April 29 to June 25, 2021. A sample size of 353 was determined using the formula for crosssectional studies. ${ }^{14}$ Multistage random sampling techique was employed in the selection process. One Local Government Area (LGA) each was selected from the 3 senatorial zones using simple random sampling by balloting. Two wards were selected from each of the selected LGAs using simple random sampling by balloting. A total of twelve settlements were selected from the list of the settlements and the population of the eligible study subjects, using simple random sampling by balloting.

The households were numbered in the settlements to get the sampling frame and the sampling interval was calculated. A number was randomly selected between one and the sampling interval to enable the commencement of the selection of households. Respondents were interviewed in their households until the required sample size was gotten. When no one was found present in a selected household, the next house was sampled.

Data was collected by using an interviewer-administered questionnaire consisting of open and closed ended questions adapted from a WHO document on indicators for assessing infant and young child feeding practices. ${ }^{15}$ It also contained questions on socio-demographic characteristics of the respondents. The respondents' socio-economic status was assessed using Oyedeji's classification of Socio-economic Index Score. ${ }^{16}$

In this study, initiation of breastfeeding within one hour of 
delivery was considered early, and exclusive breastfeeding referred to the practice of giving the infant only breast milk for six months without any fluids except liquid medicines. Breastfeeding for at least two years was considered adequate in this study. A caregiver in this study referred to a female family member apart from the mother, who breastfed or was still breastfeeding a child in place of the mother.

Open Data Kit (ODK) was installed on all the researchers' smart phones or tablets via Google play store. The validated questionnaire was downloaded from the internet server into the mobile phones and tablets and was subsequently used to collect data on the field. Completed forms were downloaded from ODK server in IBM $^{\circledR}$ SPSS version 25. This was followed by exploratory data analysis which involved running descriptive statistics of all variables and use of frequency distribution tables to present results. Frequency, percentages, and measures of central tendency were used for univariate analysis. Chi-square and Fisher's exact test were performed to assess for existence of association between independent socio-demographic and obstetric variables (such as age, parity, marital status, tribe, religion, socioeconomic status, community setting, attendance of antenatal clinic, term of delivery, place of delivery, mode of delivery) and breastfeeding practice of mothers or caregivers. Logistic regression was used to determine the variables that were independently associated with breastfeeding practices. Strength of associations was measured using adjusted odds ratio (aOR) at $95 \%$ confidence intervals (CIs). The level of statistical significance was set at $p$ - value $<0.05$.

\section{Ethical Consideration}

Ethical approval for this study was obtained from Sokoto State Ministry of Health Ethics Committee (Ref. No. $\mathrm{SMH} / 1580 / \mathrm{V}$. IV). Permission to carry out the study was sought from the respective LGA authorities and district heads of the communities. In addition, written informed consent was obtained from the study participants after explaining the objectives of the study to them.

\section{Results}

Socio-demographic characteristics of the respondents

There was a total of 353 respondents. Their ages ranged from 18-50 years, with a mean $( \pm \mathrm{SD})$ age of $28.8 \pm 6.1$ years. Majority 304(86.1\%) were between the ages of 20-35 years. Most 330(93.5\%) of the respondents were married and had three or more numbers of children. More than half $179(50.7 \%)$ of the respondents had no formal education and $285(80.5 \%)$ were petty traders. Larger proportion $180(51.0 \%)$ of the respondents were of low socio-economic status as shown in Table 1.

\section{Respondents' Obstetric history}

Most of the respondents attended antenatal clinic with a frequency of attendance of $<8$ times in 293(83.0\%) of them. Pregnancy was carried to term in the majority $314(89.0 \%)$ of them with the home environment being the commonest $203(57.5 \%)$ place of delivery, and spontaneous vaginal delivery being the commonest $320(90.7 \%)$ mode of delivery (Table 2).

\section{Respondents' breast-feeding practices}

All 353(100.0\%) the respondents practiced breastfeeding at some point in time. Breastfeeding was initiated immediately (within the first hour of delivery) by 252(71.4\%) of respondents. The absence of breast milk was the main
Table 1: Sociodemographic characteristics of the respondents

\begin{tabular}{|c|c|c|}
\hline Variables & Frequency ( $n=353$ ) & Percent \\
\hline \multicolumn{3}{|l|}{ Mother/caregiver Age (years) } \\
\hline$<20$ & 7 & 2.0 \\
\hline $20-35$ & 304 & 86.1 \\
\hline $36-50$ & 42 & 11.9 \\
\hline \multicolumn{3}{|l|}{ Mean $=28.8 \pm 6.1$ years } \\
\hline \multicolumn{3}{|l|}{ Marital status } \\
\hline Single & 5 & 1.4 \\
\hline Married & 330 & 93.5 \\
\hline Divorced & 9 & 2.5 \\
\hline Widowed & 9 & 2.5 \\
\hline \multicolumn{3}{|l|}{ Parity } \\
\hline 1 & 31 & 8.8 \\
\hline 2 & 47 & 13.3 \\
\hline$\geq 3$ & 275 & 77.9 \\
\hline \multicolumn{3}{|l|}{ Tribe } \\
\hline Hausa & 248 & 70.3 \\
\hline Fulani & 80 & 22.6 \\
\hline Yoruba & 1 & 0.3 \\
\hline Igbo & 1 & 0.3 \\
\hline $\begin{array}{l}\text { Others (Igbira, Barebari, kanuri, } \\
\text { kambari) }\end{array}$ & 23 & 6.5 \\
\hline \multicolumn{3}{|l|}{ Religion } \\
\hline Islam & 351 & 99.4 \\
\hline Christianity & 2 & 0.6 \\
\hline \multicolumn{3}{|l|}{ Mother/ caregiver education } \\
\hline Tertiary & 19 & 5.4 \\
\hline Secondary & 109 & 30.9 \\
\hline Primary & 46 & 13 \\
\hline Arabic school/ Not literate & 179 & 50.7 \\
\hline \multicolumn{3}{|l|}{ Mother/ caregiver occupation } \\
\hline $\begin{array}{l}\text { Nurse/ Senior school teacher or } \\
\text { intermediate level civil servant }\end{array}$ & 4 & 1.1 \\
\hline Primary school teacher/ Driver or Artisan & 9 & 2.5 \\
\hline Laborer or Petty trader & 284 & 80.5 \\
\hline Unemployed/Full time & 56 & 15.9 \\
\hline \multicolumn{3}{|l|}{$\begin{array}{l}\text { Socioeconomic status of mother/ } \\
\text { caregiver }\end{array}$} \\
\hline Upper class & 33 & 9.3 \\
\hline Middle class & 140 & 39.7 \\
\hline
\end{tabular}

$61(60.4 \%)$ reason provided by respondents' that were unable to initiate breastfeeding at birth. Other less frequent reasons were family tradition and bathing of the child immediately after delivery $9(8.9 \%)$. Colostrum was fed 
Table 2: Obstetric history of the respondents

\begin{tabular}{lll}
\hline Variables & Frequency $(\mathbf{n}=\mathbf{3 5 3})$ & Percent \\
\hline Attend ANC & & \\
Yes & 338 & 95.8 \\
No & 15 & 4.2 \\
Frequency of ANC & & \\
$<8$ & 293 & 83.0 \\
$\geq 8$ & 60 & 17.0 \\
Term of delivery & & \\
Term & 314 & 89.0 \\
Preterm & 1 & 0.3 \\
Post term & 38 & 10.8 \\
Place of delivery & & \\
Hospital & 149 & 42.2 \\
Home & 203 & 57.5 \\
Others (on the way to the hospital) & 1 & 0.3 \\
Mode of delivery & & \\
Spontaneous vaginal delivery & 320 & 90.7 \\
Assisted vaginal delivery & 19 & 5.4 \\
Caesarean section & 14 & 4.0 \\
\hline ANC=Antenatal Care & &
\end{tabular}

$\overline{\mathbf{A N C}}=$ Antenatal Care

uninterruptedly to $347(98.3 \%)$ of the children. A majority $287(81.3 \%)$ of them did not practice exclusive breastfeeding in the first six months with the main $158(55.1 \%)$ reason been non-availability of enough breast milk. Water was offered in addition to breast milk, by $30.7 \%$ of respondents while plain pap was the main $92(32.0 \%)$ type of food offered by the respondents within the first six months. About $43.3 \%$ of the children were breastfed on demand. As at the time of this study, $120(34.0 \%)$ of the children were still breastfeeding. Majority $160(47.0 \%)$ of the respondents that had stopped breastfeeding their children did so between 19-24 months of age, with the main $200(85.8 \%$ ) reason being that children were old enough (Table 3).

Association between socio-demographics, obstetric history, and initiation of breastfeeding

There was no significant association between maternal age $(p=0.970)$, marital status $(p=0.653)$, parity $(p=0.319)$, tribe $(\mathrm{p}=0.318)$, religion $(\mathrm{p}=1.000)$, socio-economic status $(\mathrm{p}=$ $0.489)$, community setting $(\mathrm{p}=0.637)$, antenatal clinic attendance $(\mathrm{p}=0.770)$, term of delivery $(\mathrm{p}=0.127)$, place of delivery $(p=0.363)$, and mode of delivery $(p=0.168)$, with the timing of respondents' initiation of breastfeeding.

Association between socio-demographic factors and exclusive breastfeeding practice of respondents

Whereas there was no significant statistical association between respondents' age $(p=0.238)$, tribe $(p=1.000)$, religion $(\mathrm{p}=0.641)$ with exclusive breastfeeding practice, it was however found to be associated with parity and socioeconomic status. The proportion of the respondents 58(87.9) with parity $\geq 3$ who practiced exclusive breastfeeding was statistically significantly higher $(\mathrm{p}=$ $0.032)$ compared to those with parity $<3$. Socio-economic status was significantly $(\mathrm{p}=0.036)$ associated with exclusive breastfeeding practice (Table 4$)$.
Table 3: Breast-feeding practices of respondents

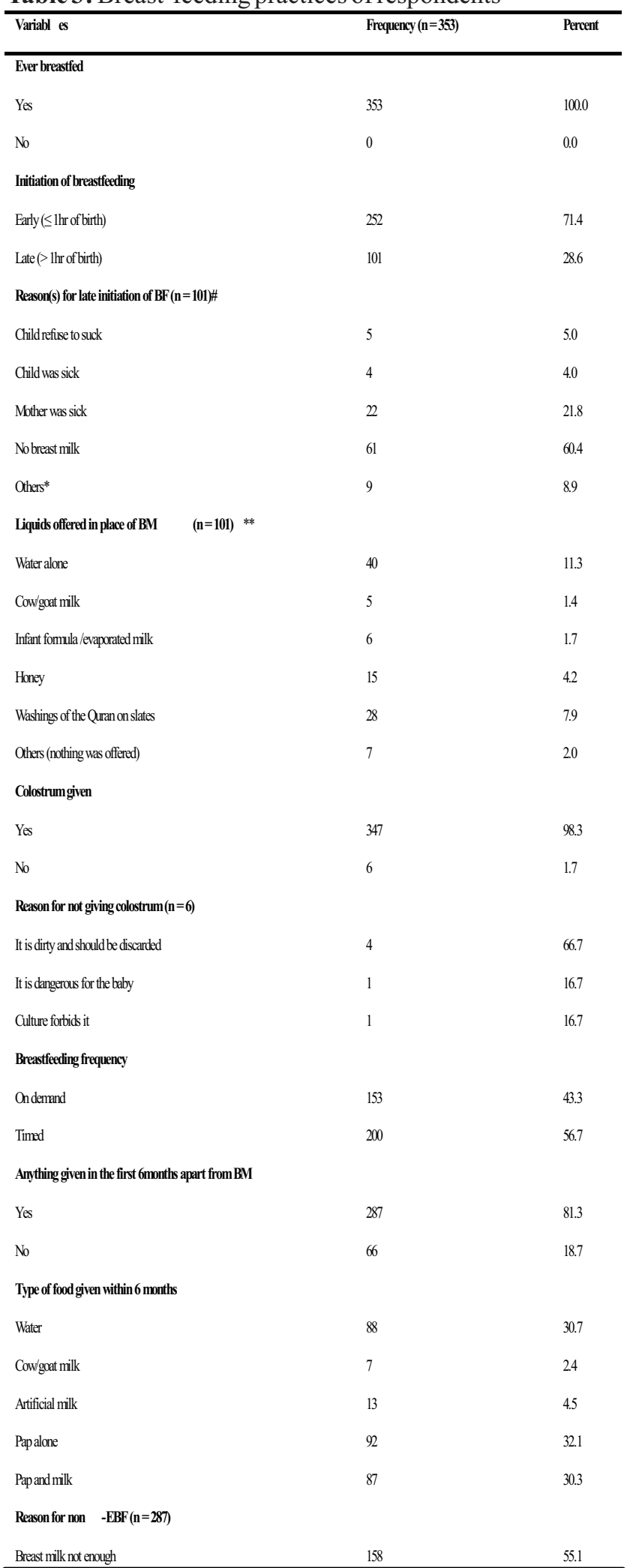

$\mathbf{B M}=$ Breast Milk, EBF $=$ Exclusive Breast Feeding; $*=$ Health personnel held the baby over; baby was taken home to bath; family tradition; $* *=$ Multiple responses allowed; \# = Multiple responses allowed; \#\# = mother observing fast, child showing interest, complementing; traditional medication, no felt need for EBF; ***= Child's sickness, mother's sickness, mother dislikes suckling

Association between respondents' obstetric history and exclusive breastfeeding practice

There was statistically significant association between respondents mode of delivery $(\mathrm{p}=0.040)$ and the practice of exclusive breast-feeding. However, there was no association 
Table 4. Association between socio-demographic factors and exclusive breastfeeding practice.

\begin{tabular}{|c|c|c|c|}
\hline \multirow[t]{2}{*}{ Variable } & \multicolumn{2}{|c|}{ Practice category $(n=353)$} & \multirow{2}{*}{$\begin{array}{l}\text { Test statistic } \\
\text { p value }\end{array}$} \\
\hline & $\begin{array}{l}\text { EBF } \\
\text { n }(\%)\end{array}$ & $\begin{array}{l}\text { No EBF } \\
\text { n }(\%)\end{array}$ & \\
\hline \multicolumn{4}{|c|}{ Mother/ caregiver's age (years) } \\
\hline$\leq 35$ & $56(84.8)$ & $255(88.9)$ & \multirow{2}{*}{$\begin{array}{l}\text { Fisher's exact } \\
\mathrm{p}=0.238\end{array}$} \\
\hline$>35$ & $10(15.2)$ & $32(11.1)$ & \\
\hline \multicolumn{4}{|c|}{ Marital status } \\
\hline Single & $0(0.0)$ & $5(1.7)$ & \multirow{4}{*}{$\begin{array}{l}\text { Fisher's exact } \\
p=0.287\end{array}$} \\
\hline Married & $65(98.5)$ & $265(92.3)$ & \\
\hline Divorced & $1(1.5)$ & $8(2.8)$ & \\
\hline Widowed & $0(0.0)$ & $9(3.1)$ & \\
\hline \multicolumn{4}{|l|}{ Parity } \\
\hline$<3$ & $8(12.1)$ & $70(24.4)$ & \multirow{3}{*}{$\begin{array}{l}\text { Fisher's exact } \\
\mathbf{p}=\mathbf{0 . 0 3 2}\end{array}$} \\
\hline$\geq 3$ & $58(87.9)$ & $217(75.6)$ & \\
\hline \multicolumn{3}{|l|}{ Tribe } & \\
\hline Hausa & $57(86.4)$ & $271(94.4)$ & \multirow{4}{*}{$\begin{array}{l}\chi^{2}=6.032 \\
p=0.067\end{array}$} \\
\hline Yoruba & $0(0.0)$ & $1(0.3)$ & \\
\hline Igbo & $0(0.0)$ & $1(0.3)$ & \\
\hline Others* & $9(13.6)$ & $14(4.9)$ & \\
\hline \multicolumn{4}{|l|}{ Religion } \\
\hline Islam & $66(100)$ & 285(99.3) & \multirow{2}{*}{$\begin{array}{l}\text { Fishers exact } \\
\mathrm{p}=1.000\end{array}$} \\
\hline Christianity & $0(0.0)$ & $2(0.7)$ & \\
\hline \multicolumn{4}{|c|}{ Socioeconomic class } \\
\hline Upper class & $7(10.6)$ & $26(9.1)$ & \multirow{3}{*}{$\begin{array}{l}\chi^{2}=6.639 \\
\mathbf{p}=\mathbf{0 . 0 3 6}\end{array}$} \\
\hline Middle class & $17(25.8)$ & $123(42.8)$ & \\
\hline Lower class & $42(63.6)$ & $138(48.1)$ & \\
\hline \multicolumn{4}{|c|}{ Community setting } \\
\hline Urban & $36(45.5)$ & $131(51.2)$ & \multirow{2}{*}{$\begin{array}{l}\text { Fishers exact } \\
p=0.219\end{array}$} \\
\hline Rural & $30(54.6)$ & $156(48.8)$ & \\
\hline
\end{tabular}

*(Igbira, Barebari, kanuri, kambari)

between antenatal clinic attendance $(p=0.746)$, term of delivery $(p=0.575)$, place of delivery $(p=0.089)$, and the practice of exclusive breastfeeding.

\section{Predictors of exclusive breastfeeding practice among the respondents}

Binary logistic regression analysis revealed that, parity remained an independent predictor of respondents' exclusive breastfeeding practice. Respondents with parity $<3$ were 0.2 times less likely to practice exclusive breastfeeding compared to those with parity of $\geq 3$ (Table 5).

\footnotetext{
Association between respondents' socio-demographic characteristics, obstetric history, and weaning

There was no significant association between respondents' age $(\mathrm{p}=0.614)$, marital status $(\mathrm{p}=0.404)$, parity $(\mathrm{p}=0.513)$, tribe $(p=0.574)$, religion $(p=0.943)$, socio-economic status $(p=0.195)$, community setting $(p=0.437)$, antenatal clinic attendance $(\mathrm{p}=1.000)$, term of delivery $(\mathrm{p}=0.645)$, place of delivery $(p=1.000)$, mode of delivery $(p=0.569)$, and respondents' timing of weaning.
}

\section{Discussion}

This study has assessed the breastfeeding practices of mothers and caregivers of children in Sokoto, North-western part of Nigeria. The respondents in this study were of a relatively young population, and majority of them were married. These findings are similar to what was reported previously from Kaduna, Nigeria. ${ }^{7}$ Although there were some proportions of Christians and tribes including Yoruba and Igbo, the preponderance of Muslims and Hausas in this study is a reflection of the study area, which predominantly comprises of Muslims and people of Hausa ethnicity. ${ }^{17}$

Similar to report from Kaduna state, Nigeria, ${ }^{7}$ more than half of the respondents in this study had no formal education and majority were either petty traders or not gainfully employed. The lower literacy rate in this study is not unrelated to the fact that in Sokoto State, the study area, the proportion of out of school children and literacy amongst women is very low. ${ }^{18}$ Female education has been described as one of the strongest determinants of EBF. ${ }^{19}$ In the study area, girls are usually married out at early ages in most cases before they attain their fifteenth birthday after attaining Qur'anic education and sometimes immediately after completion of secondary 
Table 5: Predictors of the practice of exclusive breastfeeding

\begin{tabular}{|c|c|c|c|c|}
\hline \multirow[t]{2}{*}{ Variables } & \multirow[t]{2}{*}{ aOR } & \multicolumn{2}{|c|}{$95 \%$ CI } & \multirow[t]{2}{*}{ p-value } \\
\hline & & lower & Upper & \\
\hline $\begin{array}{l}\text { Mother/ caregiver's parity } \\
\left(<3 \mathrm{vs} \geq 3^{*}\right)\end{array}$ & 0.428 & 0.195 & 0.939 & 0.034 \\
\hline $\begin{array}{l}\text { Socioeconomic class } \\
\text { (Upper class vs Lower class*) }\end{array}$ & 0.885 & 0.358 & 2.183 & 0.790 \\
\hline $\begin{array}{l}\text { Socioeconomic class } \\
\text { (Middle class vs Lower class*) }\end{array}$ & 0.454 & 0.246 & 0.839 & 0.051 \\
\hline $\begin{array}{l}\text { Mode of delivery } \\
\text { (Spontaneous vaginal* vs Caesarean section) }\end{array}$ & 0.970 & 0.240 & 3.918 & 0966 \\
\hline $\begin{array}{l}\text { Mode of delivery } \\
\text { (Spontaneous vaginal* }^{*} \text { vs Assisted vaginal) }\end{array}$ & 0.490 & 0.165 & 1.463 & 0.198 \\
\hline
\end{tabular}

$\mathbf{a O R}=$ Adjusted Odds Ratio $\quad \mathbf{C I}=$ Confidence Interval $*=$ Reference group

school education. ${ }^{18}$ Evidence suggests that adolescent and young mothers are more physiologically and socioeconomically disadvantaged and these disadvantages may lead to higher occurrence of poor breastfeeding practices and worse health outcomes among their children. ${ }^{20-}$ 22

The finding of all respondents breastfeeding their children at some point in time is comparable to those of studies conducted in Giwa, Kaduna state, and in Kware, Sokoto state both of which are communities located in the same zone with the study area. ${ }^{7,8}$ Breastfeeding has numerous advantages. However, the benefits are more likely to impact on the health and well-being of children where appropriately practiced. ${ }^{23}$ Respondents' choice of breastfeeding their children in this study being comparable to the other studies could be attributed to their cultural practices being similar. More so, breast-feeding practices to some extent, have been said to be dependent on culture. ${ }^{24}$ Perhaps, children born in cultural setups such as in the study area, where breastfeeding is acceptable might've higher chances of being commenced on breastfeeding immediately at birth, with increasing likelihood of being exclusively breastfed. The finding in this study is also a further confirmation that breastfeeding is a culturally acceptable practice in many ethnic groups in Nigeria, ${ }^{18}$ in addition to high level of awareness of breastfeeding being attributed to the high proportion of some form of breastfeeding among mothers in Nigeria. ${ }^{25-27}$ This study observed that a good number of respondents (71.4\%) practiced early initiation of breastfeeding. This finding is in consonance with the report of $72.2 \%$ from a study conducted in India, ${ }^{28}$ but contrasts with the earlier reports of studies conducted in the study area, and in other parts of Nigeria and
Africa, where lower rates of early initiation of breastfeeding were documented..$^{7,84,29,30}$ Initiation of breastfeeding within the first hour of life is important for both the mother and the child. The first breast milk contains colostrum, which is highly nutritious and has antibodies that protect the newborn from diseases. Early initiation of breastfeeding has the advantage of stimulating lactation and has been documented to play a role in enhancing maternal-infant bonding, with improvement in child survival. ${ }^{18,23,31}$ Despite the fact that all children in this study were breastfed, the practice of exclusive breastfeeding was however, suboptimal, with implications of denying children the benefits of EBF and exposing them to under-nutrition and its numerous consequences. Although the rate is higher than those of reports from studies conducted in Kaduna and Bauchi in Northern Nigeria, ${ }^{7,32}$ it is however, below the rates of $28.7 \%$, $37.3 \%$, and $36.6 \%$ reported from South-west, South- east, and South-south Nigeria, respectively. ${ }^{10,11,27}$

The main reasons for non -exclusive breastfeeding practice by respondents in this study being hot weather and breast milk not being enough to satisfy the baby could be a reflection of the mothers' level of knowledge of the importance of exclusive breastfeeding, as well as misconceptions regarding breast milk not being enough to quench the thirst of infants. The practice of early introduction of liquids or other feeds in the first six months of life has been reported to be associated with increasing tendency of malnutrition, infectious diseases, morbidity, and mortality. ${ }^{23}$ The average duration of breastfeeding of 19.5 months $( \pm 2.3)$ by majority of the respondents in this study fell short of WHO recommendation of at least 24 months. Breast milk provides up to a third of the energy and nutrient 
needs of children in the second year of life. Longer duration of breastfeeding also contributes to reducing the risk of ovarian and breast cancers and helps in child spacing. ${ }^{33}$ The implication of the finding in this study is that, on the average, children and respondents in this study could not receive the full complement of the aforementioned health benefits of adequate breastfeeding. The breastfeeding duration is in keeping with an earlier study conducted in the study area and in Indonesia, but slightly higher than the reported national average breastfeeding duration of 18.5 months, and the average of 15 months reported from southern Nigeria., ${ }^{4,810,18}$

The finding of respondents with higher parity being more likely to practice exclusive breastfeeding in this study is commensurable with report from South-east Nigeria, ${ }^{11}$ a contrary finding was obtained from a study in South-west Nigeria. ${ }^{24}$ Mothers or caregivers with higher parity are likely to have acquired more knowledge and experience overtime, regarding the importance of exclusive breastfeeding, and this could influence their practice compared to the young inexperienced ones. The finding in this study of respondents in the urban and rural community setting having similar practice of exclusive breastfeeding is in synergy with the report from Lagos where there was no difference in the breastfeeding practices of mothers from both urban and rural communities. 'The fact that urban dwellers are more at an advantage in terms of access to educational and other social amenities that could translate to positive attitude towards breastfeeding makes this finding quite unusual. Additionally, the absence of association between most of the respondents' socio-demographic characteristics and factors such as regular attendance of antenatal clinic visits which are expected to impact positively on their breastfeeding practices could be attributed to the effect of cultural practices and perhaps, other yet unidentified factors in the study location. Feeding practices have been observed to be influenced by cultural practices that had been passed down across generations. $^{34}$

Based on the findings in this study, it can be concluded that breastfeeding was practiced by all respondents, with most of them initiating breastfeeding immediately at birth. However, the practice of EBF was low and associated with parity and socio-economic status. Additionally, the average duration of breastfeeding was shorter than the WHO recommendation of at least 24 months. Routine health education programs and counseling sessions should be strengthened by healthcare workers in all health facilities and clinics outlets across the state with focus on breast feeding practices of mothers and other primary caregivers of children. The state government should ensure constant/regular mass media health awareness programs targeted at women of all ages, families, stakeholders in the communities, and policy makers through the radio, televisions and other channels of communication with emphasis on the importance of early initiation of breastfeeding, exclusive breastfeeding and weaning at the recommended age of at least 2 years.

This study is limited by the possibilities of recall and reporting bias, due to the fact that some questions were based on past events. Efforts to reduce these limitations were however, ensured by allowing for recap of information as well as routinely repeating selected questions to ascertain clarity and consistent responses.

\section{References}

1. Ogunlesi T, Ezechukwu CC. Digestion and absorption, nutrition, macronutrients and micronutrients. In: Azubuike, Nkanginieme, editors. Paediatrics and Child Health in a Tropical Region. 3 ed. Lagos, Nigeria: Educational printing and publishing 2016. p. 658-69.

2. Egbuonu I, Ojukwu JU. Infant feeding. In: Azubuike, Nkanginieme, editors. Paediatrics and Child Health in a Tropical Region. 3 ed. Lagos, Nigeria: Educational printing and publishing; 2016. p. 670-89.

3. Victora CG, Bahl R, Barros AJD. Breastfeeding in the 21 st century: epidemiology, mechanisms, and lifelong effect. Lancet. 2016;387:475-90.

4. Ika RP, Susetyowati RM, Farah F. Feeding practices and nutritional status among children under five years of age in Sleman district, Yogyakarta, Indonesia. PakJ Nutr. 2019;18:888-94.

5. United Nations Children's Fund. The state of the world's children. Children, Food, and Nutrition: Growing well in a changing world. Available from https://www.unicef.org Accessed on 20/05/21. 2019.

6. Akadri A, Odelola O. Breastfeeding Practices among Mothers in Southwest Nigeria. Ethiop J Health Sci. 2020;30(5):697-706.

7. Idris S, Zakariyya BP, Sambo MN, Sufyan MB, Abubakar A Nutritional status and pattern of infant feeding practices among children under five in a rural community of Northwestern Nigeria. Int'l Quarterly of Community Health Education. 2012;33:83-94.

8. Oche OM, Umar AS, Ahmed H. Knowledge and practice of exclusive breastfeeding in Kware, Nigeria. African Health Sciences. 2011;11:518-23.

9. Sebanjo IO, Olayiwola IO, Afolabi WAO. Dietary practices and nutritional status of under-five children in rural and urban communities of Lagos State, Nigeria. Niger Med J2016;57:307-13.

10. Atimati AO, Adam VY. Breastfeeding practices among mothers of children aged 1-24 months in Egor Local Government Area of Edo State, Nigeria. South African Journal of Clinical Nutrition. 2020;33:10-6.

11. Ukegbu AU, Ukegbu PO, Onyeonoro UU, Ubajaka CF. Determinants of breastfeeding patterns among mothers in Anambra State, Nigeria. SAJCH. 2011;5:112-6.

12. Ahmad MM, Sani UM, Abolodje E, Isah BA, Mohammed BA, Garba BI. Mothers' Attitude and Practices on Breast Feeding in Sokoto, North-Western Nigeria. International Journal of Health Sciences and Research. 2017;7:20-4.

13. Yusuf T, Baba J. Complimentary feeding practices and nutritional status of young children in a community in Sokoto. Niger J Paediatr. 2020;47:324-9.

14. Araoye M. Sample Size Determination. Research Methodology with Statistics for Health and Social Sciences. Saw-mill Ilorin, Nigeria: Nathadex Publishers 2003. p. 115-29.

15. World Health Organization. Infant and Young Child Feeding: Model Chapter For Textbooks For Medical Students and Allied Health Professionals. Geneva: WHO Press. 2009.

16. Oyedeji G. Socioeconomic and Cultural Background of Hospitalized Children in Ilesha. Niger J Paediatr. 1985;12:111-7.

17. The editors of Encyclopaedia Britannica. Sokoto. Encyclopaedia Britannica. Encyclopaedia Britannica, inc $U R L$ http://www.britannica.com/place/Sokoto-state-Nigeria. 2012.

18. National Population Commission \& ICF. Nigeria Demographic and Health Survey 2018. Abuja, Nigeria, and Rockville, Maryland, USA. 2019.

19. Dubois L, Girard M. Social determinants of initiation, duration and exclusivity of breastfeeding at the population level. The results of a longitudinal study of child development in Quebec (ELDEQ 19982002). Canadian J Public Health. 2003;94(4):300-5

20. Amin T, Hablas H, Al Qader A. Determinants of initiation and exclusivity of breastfeeding in al Hassa, Saudi Arabia. Breastfeed Med. 2011;6:59-68

21. Finlay JE, Özaltin E, Canning D. The association of maternal age with infant mortality, child anthropometric failure, diarrhoea and anaemia for first births: evidence from 55 low- and middle-income countries. BMJOPEN 1:e000226.2011. 
22. Nukpezah R, Nuvor S, Ninnoni J. Knowledge and practice of exclusive breastfeeding among mothers in the tamale metropolis of Ghana. Reprod Health. 2018;15:140

23. World Health Organization. Early child development - Nutrition and the early years. Available from https://www.who.int/topics/earlychild-development/child-nutrition/en/Accessed on 17/05/21.2021.

24. Adebayo A, Oluwaseyi O. Breastfeeding Practices among Mothers in Southwest Nigeria. Ethiop J Health Sci. 2020;30:697-706.

25. Balogun MR, Okpalugo OA, Ogunyemi AO, Sekoni AO. Knowledge, attitude, and practice of breastfeeding: A comparative study of mothers in urban and rural communities of Lagos, Southwest Nigeria. Niger MedJ. 2017;58:123-30.

26. Onah S, Osuarah DIC, Ebenebe J, Ezechukwu C, Ekwochi U, Ndukwu I. Infant feeding practices and maternal sociodemographic factors that influence practice of exclusive breastfeeding among mothers in Nnewi south- East Nigeria: a cross-sectional and analytical study. Int Breastfeed J. 2014;9:6.

27. Sadoh AE, Sadoh WE, Oniyelu P. Breast feeding practice among medical women in Nigeria. Nigeria Med J. 2011;51:7-12.

28. Chandrashekhar TS, Joshi H, Shankar PR, S, B. V. , Rana MS Breastfeeding Initiation and determinants of Exclusive breastfeedinga questionnaire survey in an urban population of Western Nepal. Public Health Nutrition. 2007;9:192-7.
29. Elyas L, Mekasha A, Admasie A, Assefa E. Exclusive breastfeeding practices and associated factors among mothers attending private pediatric and child clinics, Addis Ababa, Ethiopia: a cross-sectional study. Int J Pediatr 8546192 doi: 101155/2017/8546192. 2017.

30. Fosu-Brefo R, Arthur E. Effect of timely initiation of breastfeeding on child health in Ghana. Health Econ Rev. 2015;5:8.

31. Ghimire U. The effect of maternal health service utilization in early initiation of breastfeeding among Nepalese mothers. Int Breastfeed $J$ https://doiorg/101186/s13006-019-0228-7, 14,33.2019

32. Iliyasu Z, Sabitu K, Mohammed LS. Impact of BFHI on maternal knowledge, attitudes and practice of breastfeeding in Azare, Northern Nigeria. Nigeria Journal of Basic and Clinical Sciences. 2004;1:1522

33. World Health Organization. Infant and young child feeding. Available from https://wwwwhoint/news-room/fact-sheets/detail/infant-andyoung-child-feeding Accessed on 17/09/21.2021.

34. Oloko M, Ekpo R. Exploring Traditional Weaning practices in North Western Nigeria; Food, Knowledge and Culture: A Step towards Safeguarding Community Food Security. Academic Journal of Interdisciplinary Studies. 2018;7:97-106. 